\title{
Annual Variations of Sea Surface Elevation and Currents over the Scotian Shelf and Slope
}

\author{
GuOQI Han, * C. L. TANG, AND P. C. SMith \\ Fisheries and Oceans Canada, Bedford Institute of Oceanography, Dartmouth, Nova Scotia, Canada
}

(Manuscript received 21 February 2001, in final form 25 October 2001)

\begin{abstract}
TOPEX/Poseidon (T/P) altimeter data over the period 1992-98 have been analyzed to examine annual variability of sea surface elevation and currents over the Scotian Shelf and Slope. A modified orthogonal response analysis is used to derive the annual cycle while simultaneously removing the residual tides and other dynamical processes at the appropriate T/P alias periods. An evaluation of the $M_{2}$ and $K_{1}$ alias variations is carried out, suggesting notable tidal correction errors off Cape Cod and over Georges Bank. The along-track sea surface slopes, which represent surface geostrophic current components normal to the track, are estimated on selected $\mathrm{T} / \mathrm{P}$ ascending and descending ground tracks. The annual altimetric sea level harmonic is compared with steric height anomalies and wind-driven setup. The comparison indicates that the altimetric sea surface elevation variability is dominated by the baroclinic (and associated barotropic) component and supplemented by the winddriven and remotely forced components. Altimetric elevations agree favorably with tide-gauge data at Halifax, Nova Scotia, and well with those at St. John's, Newfoundland. Wintertime intensification of the shelf-break flows is indicated in the altimetric surface currents, consistent with the solutions of regional diagnostic model forced by baroclinicity and boundary flows. Altimetric results clearly demonstrate seasonal variability of northeastward slope current stronger in fall and winter and weaker in spring and summer, which is less well resolved in the model. Assimilation of altimetric data into regional circulation models could help improve their prognostic ability to hindcast and nowcast seasonal variability of shelf-edge and slope water circulation. This study also implies a demand for better shelf tidal models to detide altimetric data for extraction of semiannual and shorterperiod processes.
\end{abstract}

\section{Introduction}

Circulation over the Scotian Shelf and Slope off the Canadian Atlantic coast is dominated by southwestward shelfbreak and inner-shelf flows and by an eastwardflowing slope current (Fig. 1a). The southwestward flows are mainly induced by freshwater of Arctic origin (Drinkwater et al. 1979; Smith and Schwing 1991; Loder et al. 1998), supplemented by the Cabot Strait outflow from the Gulf of St. Lawrence. The Cabot Strait outflow has two major pathways on the Scotian Shelf: one is along the inner Scotian Shelf as part of the Nova Scotian Current; the other is along the shelf edge (Sutcliffe et al. 1976; Han et al. 1999). The southwestward shelfedge current was also discussed by Csanady (1979), who showed that in spring there is a sharp drop in the steric setup across the shelf break and upper continental slope

\footnotetext{
* Current affiliation: Fisheries and Oceans Canada, Northwest Atlantic Fisheries Centre, St. John's, Newfoundland, Canada.

Corresponding author address: Dr. Guoqi Han, Biological and Physical Oceanography, Northwest Atlantic Fisheries Centre, P.O. Box 5667, St. John's, NF A1C 5X1, Canada.

E-mail: Hang@dfo-mpo.gc.ca
}

extending from the Grand Banks to the western end of the Scotian Shelf. The eastward slope current is a less well-known feature. Temporal and spatial variations of its structure and transport, associated with a change in the slope/shelf front, are not well understood (Pickart et al. 1999).

Recent numerical model studies (e.g., Han et al. 1997, 1999), supported by sparsely distributed moored measurements, have produced more detailed seasonal circulation patterns for this region. These studies point to model limitations due to data sparsity and the specification of the open boundary condition. The winter intensification in the modeled shelfbreak and upper slope currents over the eastern Scotian Shelf and southern Newfoundland Shelf is qualitatively consistent with Han et al.'s (1993) finding from Geosat altimetry. Han et al. demonstrated that $M_{2}$ tidal errors in the Geosat data correction could obscure an annual cycle and that orbit errors prevented a direct examination of sea surface height anomalies over the Scotian Shelf and Grand Banks. In place of Schwiderski's model (1980) supplied with Geosat data, a regional hydrodynamic tide model was used to correct for Geosat data and thereby obtain robust results for annual sea surface slope variability in this region. The on-going TOPEX/Poseidon (T/P) mis- 

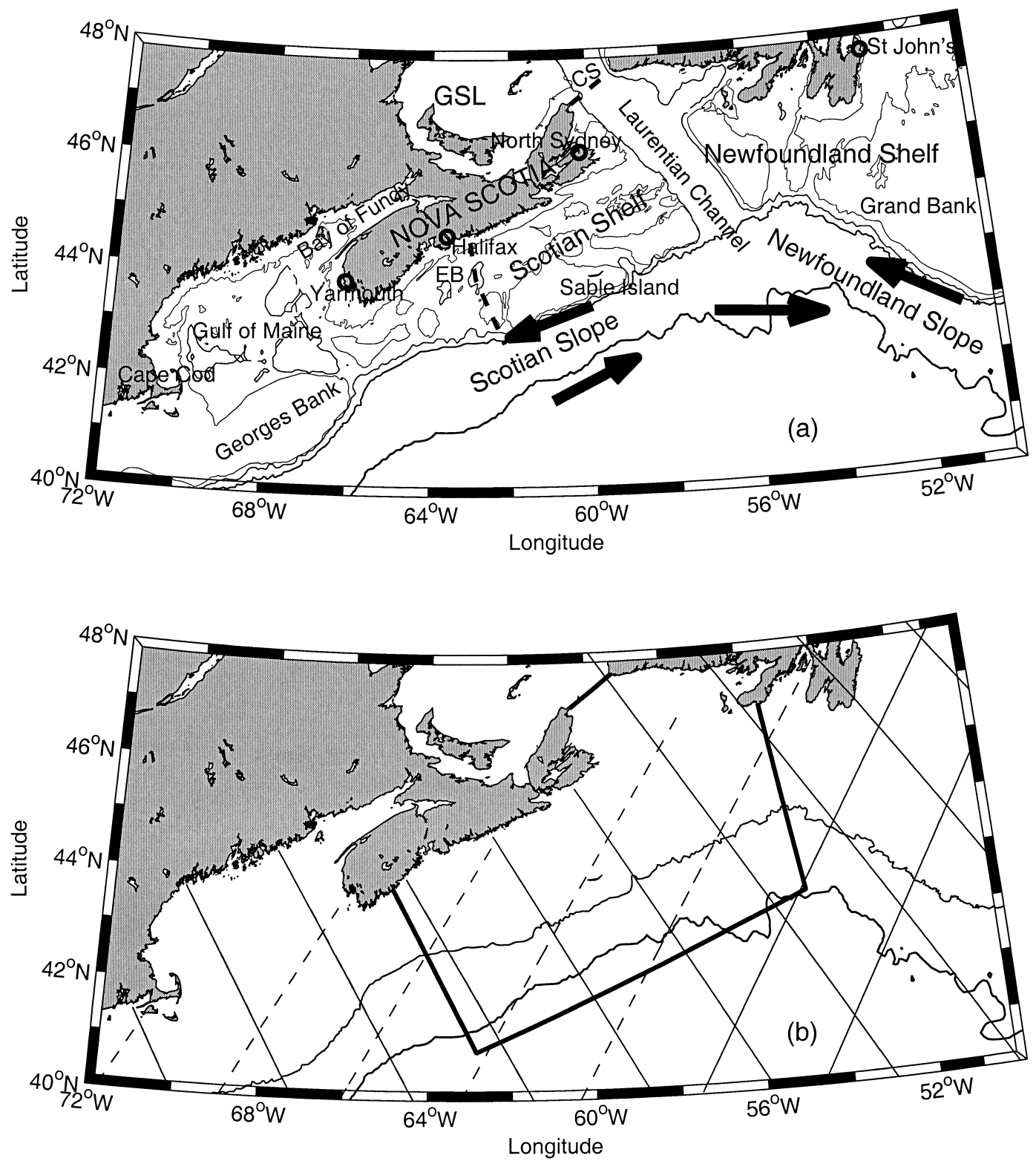

FIG. 1. (a) Map showing the study area. Open circles are the locations of coastal tide-gauge stations. The Halifax section and Cabot Strait West section are shown as the thick dashed line. The westward-flowing shelf-edge current and the eastward-flowing slope current are also depicted. The 100-, 200-, 1000- and 4000-m isobaths are also shown. CS: Cabot Strait; EB: Emerald Basin; GSL: Gulf of St. Lawrence. (b) The T/P ascending (southwest-northeast) and descending (northwest-southeast) ground tracks. T/P data on some tracks (dashed lines) are used only for estimating errors at crossovers. The thick solid lines and the appropriate coastal lines enclose the domain for a linear diagnostic model. The 1000- and 4000-m isobaths are also displayed.

sion is providing an unprecedented accuracy of $5 \mathrm{~cm}$ for a single-pass sea-surface height measurement and a $2-\mathrm{cm}$ accuracy for the temporal component. Most of the major tidal constituents in the T/P measurements are more easily separable from the annual cycle than in the Geosat data. With a broad spatial and fixed temporal distribution pattern, the high-precision T/P altimeter data have great potential to complement the existing knowledge of seasonal variability of sea level and cir- culation that is mainly based on limited in situ observations and numerical models requiring specified boundary conditions (Han and Tang 1999).

The primary purpose of this study is to examine seasonal changes of coastal sea level and shelf circulation, to distinguish wind-driven barotropic and density-driven baroclinic contributions, and to seek mechanisms underlying seasonal variability over the Scotian Shelf and Slope. We first derive the annual cycle from altimetric 
sea surface heights for each location on the selected T/ $\mathrm{P}$ ground tracks. The annual cycle of cross-track surface currents is then derived using the geostrophic approximation from the along-track sea surface slope. The altimetric sea-surface heights and currents are compared with hydrographic data and numerical model results. We then discuss forcing mechanisms underlying the seasonal variability, and the potential for assimilating altimetric measurements and in situ observations into numerical hydrodynamic models.

This paper has seven sections. In section 2, we briefly explain the technique of processing $\mathrm{T} / \mathrm{P}$ altimeter data and the methods of deriving the annual cycle of the sea level and geostrophic currents. Section 3 describes fluctuations at the alias periods of $M_{2}$ and $K_{1}$ tides, with a discussion of the tidal correction using a global tidal model. Section 4 presents the annual cycle of sea level derived from the T/P altimetry and a comparison with other data and steric height anomalies. Section 5 describes model and altimetric sea surface currents. Forcing mechanisms of the coastal sea level variability are briefly described in section 6 , and a summary is given in section 7 .

\section{Methodology}

\section{a. Altimeter data processing}

This study is based on the 1-Hz measurements of sea surface height from the United States-French T/P mission. The T/P satellite, launched in August 1992, has continued to obtain altimetric data every 10 days along its ascending and descending ground tracks. We have used data from October 1992 to May 1999. Two ascending and six descending tracks are selected for this study over the Scotian Shelf and the Grand Banks (see Fig. 1b).

Data are edited based on quality flags and parameter ranges and corrected for various instrumental and environmental effects as recommended in the user handbook (Benada 1997). Each 1-s altimetric height with an along-track resolution of $5.8 \mathrm{~km}$ is corrected for wet and dry troposphere delays, ionosphere delay, electromagnetic bias (due to ocean wave influences), inverse barometric response, and ocean load, solid Earth, and pole tides. The standard National Aeronautics and Space Administration/Goddard Space Flight Center precise orbit based on the Joint Gravity Model-3 (JGM-3) has been used to produce sea surface height data. No additional orbital error corrections are applied.

In particular, ocean tides are initially corrected using a global tidal model (Schrama and Ray 1994; its 1996 update version is actually used and is hereinafter called SR96). The remaining tidal variability will be removed in a modified response analysis.

A temporal mean sea-surface height is computed at each grid point from all available data, and then the mean is removed from the individual height data, pro- ducing sea level anomalies. Both the geoid and mean dynamic topography are removed by this procedure. The sea surface height anomalies are then analyzed using a modified response analysis to retrieve the annual cycle.

\section{b. Modified response analysis}

The response analysis was originally developed for deriving oceanic tides from altimetric data or tide-gauge data. A detailed discussion of the method can be found in Cartwright and Ray (1990) and Han et al. (1996; 2000). In essence, the time-varying portion of the tidegenerating potential for each species is expressed as a sequence of nearly orthogonal functions. A least squares regression is performed to determine spatially varying coefficients from data. There are two sets of 6 coefficients for the semidiurnal and diurnal species, respectively. These coefficients are used to calculate the admittance to the tide-generating potential for each species. The amplitude and phase at major semidiurnal and diurnal frequencies are then derived from the admittance. In this study, we have added an annual cycle to the least squares regression. As a result, the regression has a 14 spatially variable coefficients (unknowns), 12 for the semidiurnal and diurnal species and 2 (cosine and sine) for the annual cycle. We apply the method to the initially corrected T/P altimeter data (as described in the preceding subsection) to extract the annual cycle, with the remaining variability of major semidiurnal and diurnal tides being separated from it.

\section{c. Geostrophic method}

The along-track slope is calculated from the annual cycle of T/P sea level anomalies. Prior to the calculation, the annual cycle is smoothed using a moving filter with an along-track cutoff wavelength of $50 \mathrm{~km}$. The slope is then used to derive cross-track geostrophic surface current anomalies. The four descending tracks on the Scotian Shelf (three) and in Laurentian Channel (one) and the two ascending tracks on the Grand Banks are selected for the calculation of the cross-track geostrophic current. These tracks are approximately perpendicular to the direction of major shelf-scale current features of interest.

\section{Evaluation of the tidal correction}

Major semidiurnal and diurnal tides, as sensed by an altimeter, have alias periods longer than their physical periods with a sub-Nyquist sampling in satellite altimetry. With the repeat cycle of approximately 10 days for the T/P altimeter, the alias periods for $M_{2}, S_{2}, N_{2}$, $K_{1}$, and $O_{1}$ are $62,59,50,173$, and 46 days, respectively. There are natural modes of oceanic variability at these alias periods, in particular at the $K_{1}$ alias period (semiannual cycle). Therefore, the response analysis not only removes the residual tidal variability from the data, but 
a) Amplitude at the M2 alias period from T/P Data $(\mathrm{cm})$

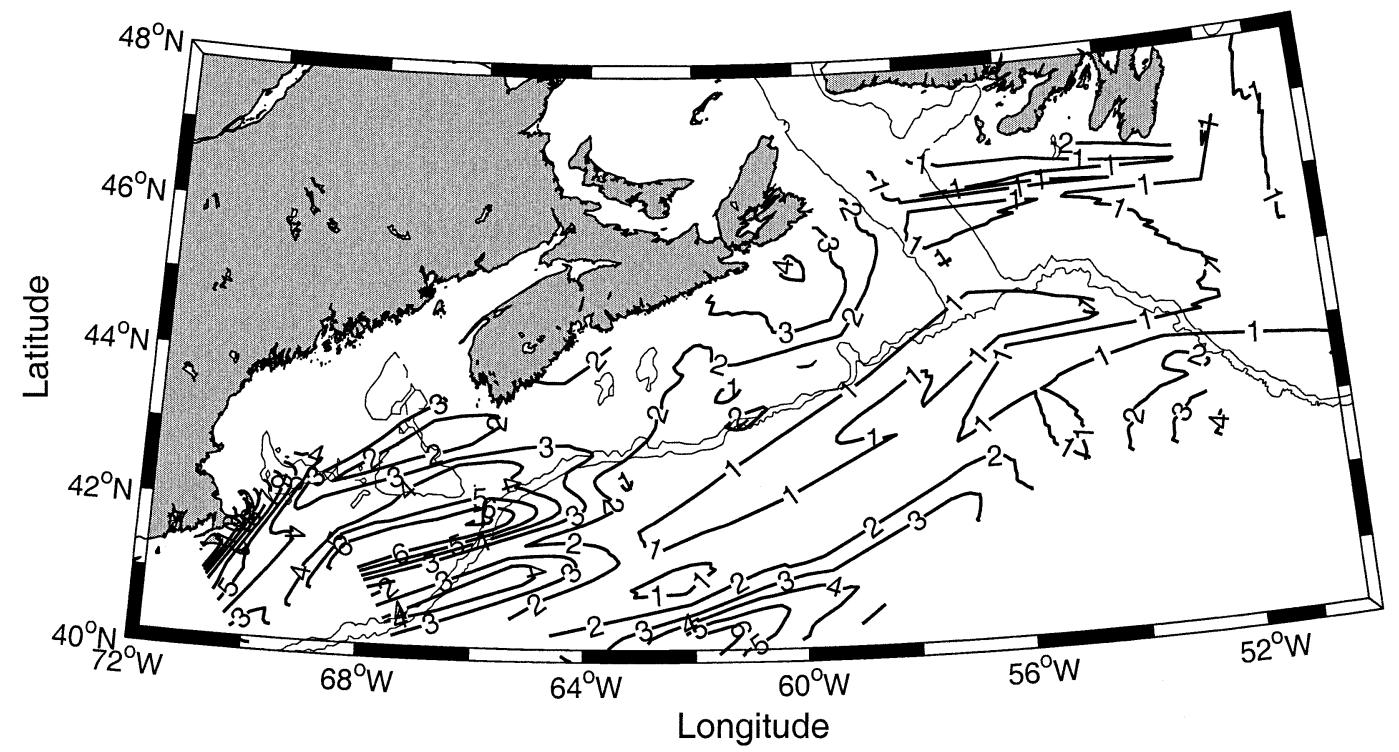

b) Amplitude at the $\mathrm{K} 1$ alias period from T/P Data $(\mathrm{cm})$

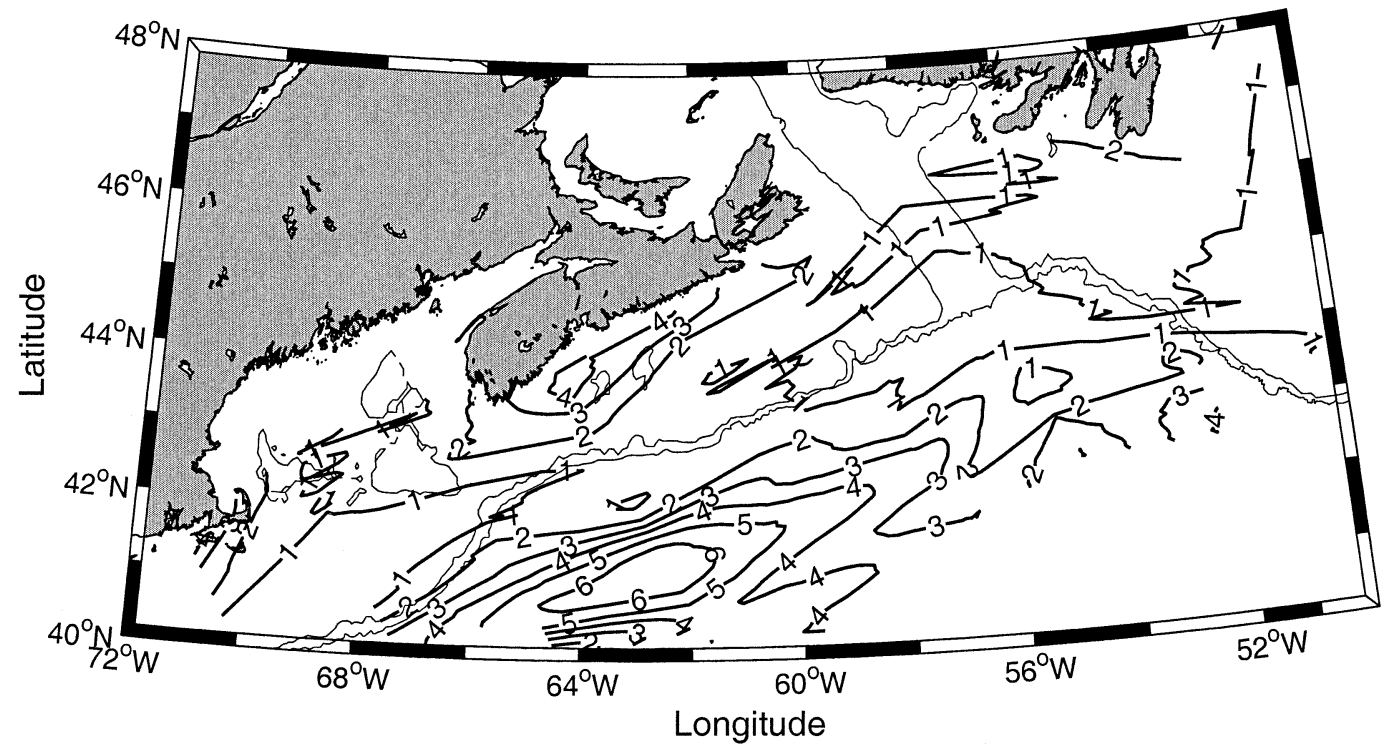

FIG. 2. Amplitudes of variations at the T/P alias periods of (a) $M_{2}$ and (b) $K_{1}$ derived from T/P altimetric data for the descending tracks. The contour interval is $1 \mathrm{~cm}$.

also reduces nontidal features at the alias periods. Nevertheless, the reduction should not significantly affect the annual cycle of interest in this study, since the alias periods for the major tides are much shorter than half a year (except for the alias period of $K_{1}$ ) and the data duration is longer than 6 years.

As pointed out in the preceding section, the SR96 global tide model was initially used to remove oceanic tides from the altimeter data in this study. The accuracy of the tide correction using a global model has long been a concern in the application of the satellite altimetry to coastal sea level variability and shelf circulation.
Han et al. (1993) showed there were significant differences in both height and slope between Schwiderski's (1980) global tide model and a local tide model for the Scotian Shelf and the Grand Banks. Although recent progress in assimilating altimetric tidal data into highresolution global hydrodynamic models has, in general, improved their accuracy within the world's shelf seas it is worthwhile making a quantitative evaluation in a study like this. This section discusses the variability at tidal alias periods removed from the tidally corrected altimeter data by the response analysis.

Figure 2 shows the spatial distribution of amplitudes 
estimated at the $M_{2}$ and $K_{1}$ alias periods from the initially corrected altimeter data. At the alias period of $M_{2}$ (Fig. 2a), the amplitude of the fluctuation is generally less than $1 \mathrm{~cm}$ in the Laurentian Channel and over the Scotian Slope and the southwestern Newfoundland Shelf. However, the amplitude over the inner Scotian Shelf is larger, up to $4 \mathrm{~cm}$. The amplitude is even larger in the Gulf of Maine and Mid Atlantic Bight. The overall magnitude there exceeds $3 \mathrm{~cm}$, with $5 \mathrm{~cm}$ over Georges Bank and $10 \mathrm{~cm}$ off Cape Cod. Brown (1998) found that subinertial bottom pressure variability in the Gulf of Maine was concentrated in the "weather band" of 2-10 days. It is probable that the residual variability at the $M_{2}$ alias period mainly represents tidal correction errors. The Gulf of Maine and Georges Bank feature large $M_{2}$ tides because of the near-resonance of the Bay of Fundy/Gulf of Maine system at semidiurnal frequencies. The large residual tide suggests an alternative model with higher accuracy should be considered in detiding altimetric data over Georges Bank and off Cape Cod.

The diurnal tides are generally weaker than the semidiurnal tides in this region. The diurnal tide system features amphidromes in the vicinity of Laurentian Channel. The earlier tidal charts based on limited in situ measurements included amphidromic points around Sable Island. However, subsequent regional numerical modeling (de Margerie and Lank 1986) and recent altimetry tide models (Han et al. 1996) placed the amphidromes in the Laurentian Channel between the eastern Scotian Shelf and the southern Newfoundland Shelf. The response analysis of the initially corrected T/P data indicates that larger variability at the $K_{1}$ alias frequency occurs over the inner Scotian Shelf, off Cape Cod and in the slope water region (Fig. 2b). The amplitude over the southwestern Newfoundland Shelf, the outer Scotian Shelf, and Georges Bank is around $1 \mathrm{~cm}$, as well as in the Laurentian Channel and the Gulf of Maine. Any substantial variability at the alias period of $K_{1}$ can be due to either the tide correction error or the semiannual variability. While the derived variability over the shelf is more likely related to the tidal fluctuation (like that at the $M_{2}$ alias frequency), the variability over the slope water region is probably due to other physical processes at the semiannual cycle.

The $M_{2}$ tide dominates the tidal height variability for the entire shelf area. Over most of the Scotian Shelf, Georges Bank, and off Cape Cod typical amplitudes of $M_{2}$ and $K_{1}$ tides are $\sim 50$ and $\sim 10 \mathrm{~cm}$ (SR96). The residual $M_{2}$ amplitude of $\sim 2 \mathrm{~cm}$ over the Scotian and southern Newfoundland Shelf is relatively insignificant, but that of $5 \sim 10 \mathrm{~cm}$ over Georges Bank and off Cape Cod is not. The residual tidal variability in the present study over the Scotian Shelf is much smaller than the discrepancy between a regional tide model and Schwiderski's model (Han et al. 1993), which indicates that the tidal correction from the SR96 global tide model is a significant improvement over Schwiderski's (1980) model. The SR96 model did a good job over the Newfoundland Shelf, the outer Scotian Shelf, and the Scotian Slope. However, better coastal and shelf tidal models, with open boundary forcing derived from latest global tidal models, are needed to detide the altimetric data for studying dynamical processes at semiannual and shorter-term scales. An improved tidal correction is particularly critical for the Gulf of Maine and adjacent areas.

\section{Annual sea level variability}

The response analysis extracted the annual cycle while simultaneously removing sea level variability at the tidal alias frequencies (discussed in the preceding section) in the T/P sea-level time series. In this section, we examine the amplitude and phase of the annual cycle of altimetric sea levels over the Scotian Shelf and Slope and over the southern Newfoundland Shelf (Fig. 3a), and compare the altimetric results with steric heights and in situ measurements.

The error associated with the extracted annual cycle is estimated by comparing results for ascending and descending T/P tracks at crossover points (Fig. 3b). At each crossover the root sum square of the cosine- and sine-term differences is referred to as the error of the annual cycle. As we can see, the estimated error is generally much smaller than the derived annual amplitude (Fig. 3a), except for two crossover points over the inner shelf: one east of Halifax and the other southeast of St. John's.

\section{a. T/P results}

Over the inner Scotian Shelf, the amplitude of the annual cycle has a maximum in excess of $5 \mathrm{~cm}$ northeast of Emerald Basin and decreases toward both the northeastern and southwestern ends of shelf (Fig. 3a). The phase (indicating the time of annual maximum sea level) pattern shows a 1-2 month lag from east to west, suggesting a southwestward propagation of the sea level signal. The highest sea level occurs in October. An apparent limitation with altimetry at present is the lack of useful information within tens of kilometers from the coast. We shall use coastal tide-gauge data (Table 1) to describe nearshore features. North Sydney features the largest annual cycle of amplitude of $4 \mathrm{~cm}$, with sea level highest in fall. In contrast, the magnitude of the annual cycle in Halifax and Yarmouth is smaller (2.4 and 1.8 $\mathrm{cm}$ ) with highest sea level in December and February, respectively, implying the southwestward propagation of the coastal sea level. Thus the coastal amplitude and phase at North Sydney is consistent with the nearby shelf values, but at Halifax coastal amplitude is smaller by a factor of 2 and the phase is delayed by the order of a month.

The amplitude of the annual cycle is $7-10 \mathrm{~cm}$ offshore in the slope water area (Fig. 3a). The sea level is highest in September, probably associated with steric effects due 

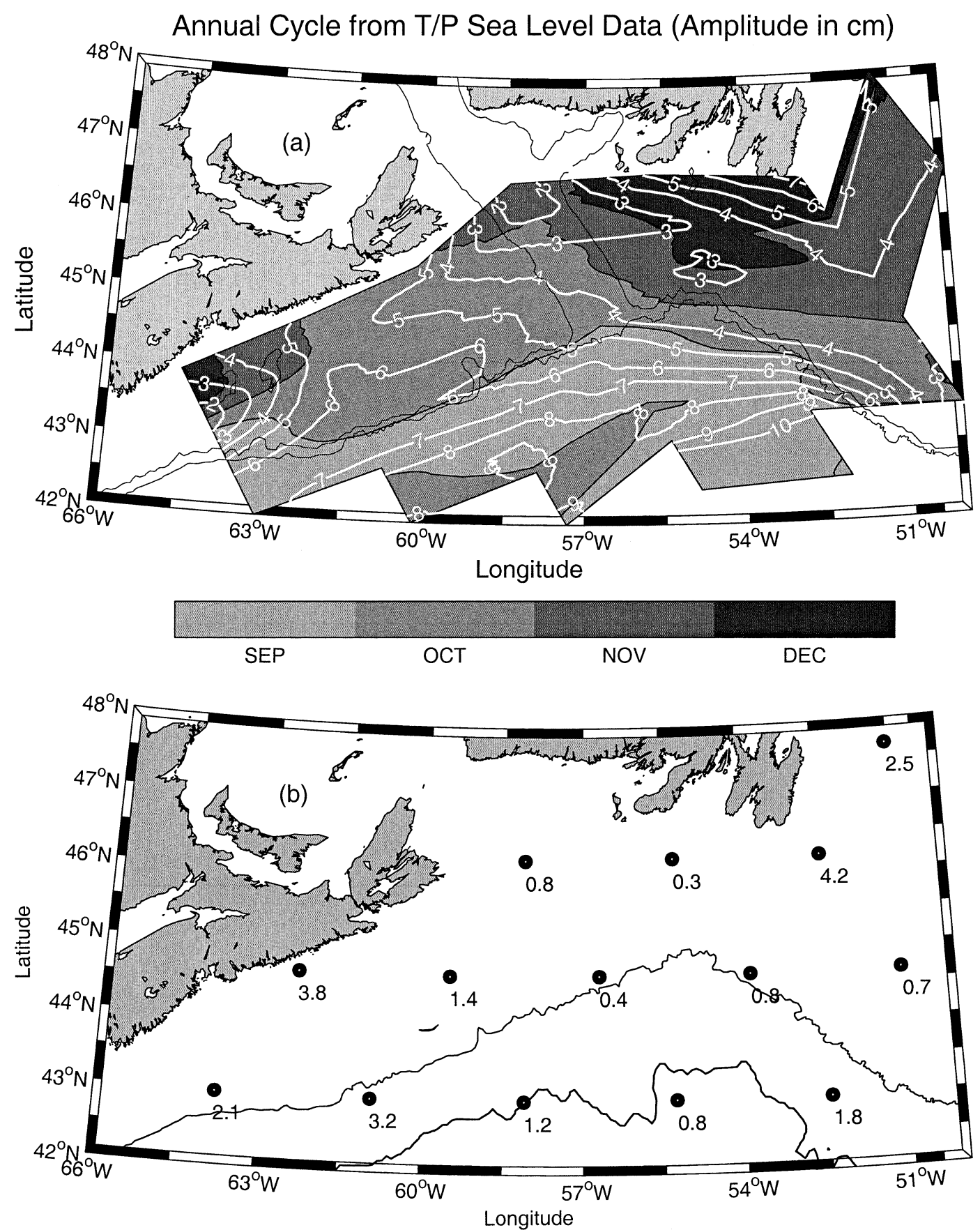

FIG. 3. (a) TOPEX/Poseidon derived annual cycle for the descending tracks on the Scotian Shelf and the Grand Banks. The amplitude contour interval is $1 \mathrm{~cm}$. The phase bands indicate the time (in months) when the annual sea level is highest. (b) Estimated errors (in $\mathrm{cm}$ ) associated with the annual cycle at crossover points.

to thermal expansion of the upper ocean in response to surface heating and cooling. The outer Scotian Shelf and the shelf edge show transitional features between those of the slope water and the inner shelf.

A minimum in the annual cycle amplitude is located in the Laurentian Channel between the Scotian Shelf and the Newfoundland Shelf. This amplitude minimum is approximately coincident and qualitatively compati- ble with the seasonally persistent circulation pattern of an inflow into the Gulf of St. Lawrence on the Newfoundland side of the Laurentian Channel and an outflow from the Gulf on the Nova Scotia side (Han et al. 1999). It also suggests a compensatory contribution of confluence of various water masses and surface heating/ cooling to seasonal steric height change in this area.

The sea level change over the southwestern New- 
TABLE 1. Amplitude $(\mathrm{cm})$ and phase (the time of annual maximum sea level) of the annual sea level harmonic derived from monthly tide-gauge data for 1992-98 adjusted for the local inverse barometric effect.

\begin{tabular}{lccc}
\hline \hline & North Sydney & Halifax & Yarmouth \\
\hline Amplitude & 4.5 & 2.4 & 2.0 \\
Phase & Nov & Dec & Feb \\
\hline
\end{tabular}

foundland Slope shows comparable amplitudes and phases to those over the Scotian Slope. Little alongslope phase change suggests broadscale surface forcing with little advective effect at the seasonal scale. Along the shelf edge near the Tail of the Grand Bank, there is a sharp change in the magnitude of the annual cycle of sea surface height. This may be associated with the intensive confluence of the Labrador Current and the slope water/Gulf Stream circulation. Off southern Newfoundland, sea level amplitude increases eastward from the Laurentian Channel. The maximum magnitude of 7 $\mathrm{cm}$ is located near St. John's. The sea level there is highest in fall and lowest in spring.

The altimetric annual cycle is also shown as snapshots on 1 February, 1 May, 1 August, and 1 November (Fig. 4), nominally for winter, spring, summer, and fall. Across the shelf edge, the sea surface slopes upward onshore in winter and downward in summer, suggesting concerted seasonal variability of the shelf-edge current along the shelf break. TOPEX/Poseidon sea level anomalies have broadscale onshore gradients over the Scotian Slope positive in spring and negative in fall, also implying substantial seasonality of the slope water current. While there is no clear realization of cross-shelf sea surface slope along the inner Scotian Shelf, the alongshelf surface slopes on both the eastern and the central Scotian Shelf are well defined suggesting significant fluctuations of cross-shelf flows in these areas. The alongshelf slope on the eastern Scotian Shelf is associated with the Gulf of St. Lawrence outflow (Han et al. 1999) and that on the central Scotian Shelf with the cyclonic gyre over Emerald Basin (Han et al. 1997). Off the south Newfoundland coast, the sea surface slope is also evident, upward onshore in winter and downward in summer.

\section{b. Comparison with steric height and tide-gauge data}

The altimetric sea surface slope across the Scotian Shelf edge (Fig. 4) is in agreement with climatological seasonal-mean steric height anomalies based on historical hydrographic data (Fig. 5). Steric height fields on 1 February (winter), 1 May (spring), and 1 August (summer), calculated relative to the 1200-m depth, are from Loder et al. (1997), and the 1 November (fall) field is calculated using their methodology. Details of constructing density climatology and computing steric height fields can be found in Loder et al. (1997). The present steric anomalies are computed by subtracting seasonal steric height fields from their mean field. We have also calculated the difference between steric height anomalies and T/P sea levels after interpolating steric height anomaly fields onto T/P data points (Fig. 6). The differences may represent the missing barotropic contribution to seasonal sea level variability in the steric height anomalies. Overall, the steric height can approximately account for altimetric sea level variability over the Scotian Shelf. However, there are substantial discrepancies between T/P and steric height anomalies over the Scotian Slope and in the winter. The large difference near the Laurentian Channel in winter may be attributed to suspect features in the steric height (Loder et al. 1997). The root mean square (rms) differences are 2.2, $1.4,1.9$, and $2.0 \mathrm{~cm}$ for winter, spring, summer, and fall respectively. The steric height anomalies have smallscale eddylike features over the Scotian Slope, which may be attributed to scarcity of historical hydrographic data.

At St. John's, the altimetric annual cycle is in good agreement with tide-gauge data (Table 2). Steric heights, calculated relative to the bottom from historical density data at Station 27 just a few kilometers off St. John's (Petrie and Anderson 1983), have smaller but substantial annual changes compared with altimetric observations. The change of steric height leads the altimetric variation by 1-2 months. On the other hand, the wind-driven sea level change calculated from a linear barotropic model for the northwestern North Atlantic forced by a climatological monthly mean wind field (Greatbatch and Goulding 1989) also has a comparable amplitude, but lags the altimetric variation by $1-2$ months. Note that the model sea level at St. John's is sensitive to the choice of the bottom drag coefficient, and the result in Table 2 corresponds to a drag coefficient of $0.0005 \mathrm{~m} \mathrm{~s}^{-1}$. The addition of the steric and wind-driven effect can account for the altimetric result reasonably well. This agreement indicates that the sea level variability at St. John's is driven mainly by steric height variations and by barotropic response to both local and North Atlantic wind forcing.

At Halifax, the extrapolated altimetric sea level has an annual cycle of $4.5 \mathrm{~cm}$ in amplitude, peaking in November (Table 3). Surprisingly, the steric height (also see Fig. 5), though calculated from density climatology, shows a similar annual variability, whereas the annual amplitude derived from the 1992-98 tide-gauge data has smaller magnitude. The wind-driven contribution to the annual sea level change, estimated from monthly mean Sable Island alongshore wind stress anomalies from 1992 to 1998 according to Smith and Schwing's (1991) study, is negligible compared with steric height variability. Greatbatch and Goulding's (1989) model result also indicates negligible wind-driven sea level change at the seasonal scale. It is worthwhile pointing out that there is significant higher frequency variability in monthly tide-gauge data, probably associated with wind-forcing as pointed out by Thompson (1986). 

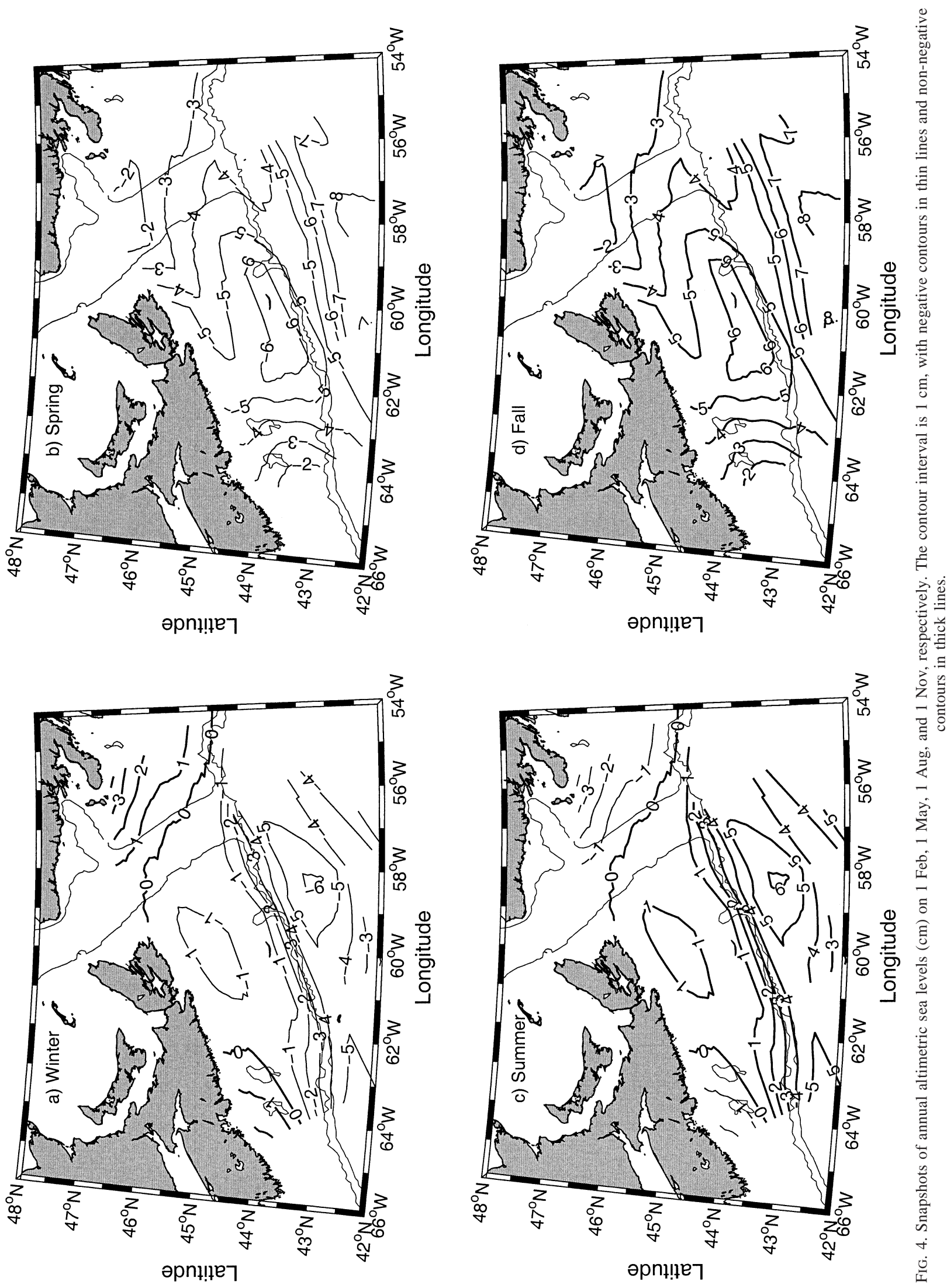


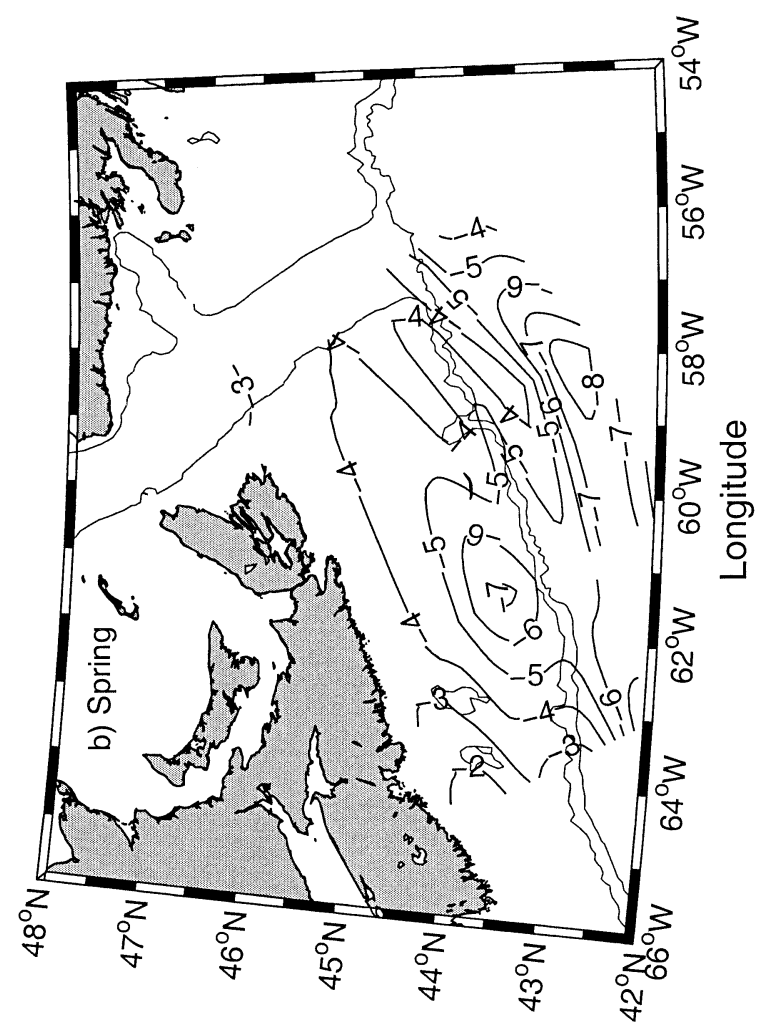

әрпџ!ฺฺ
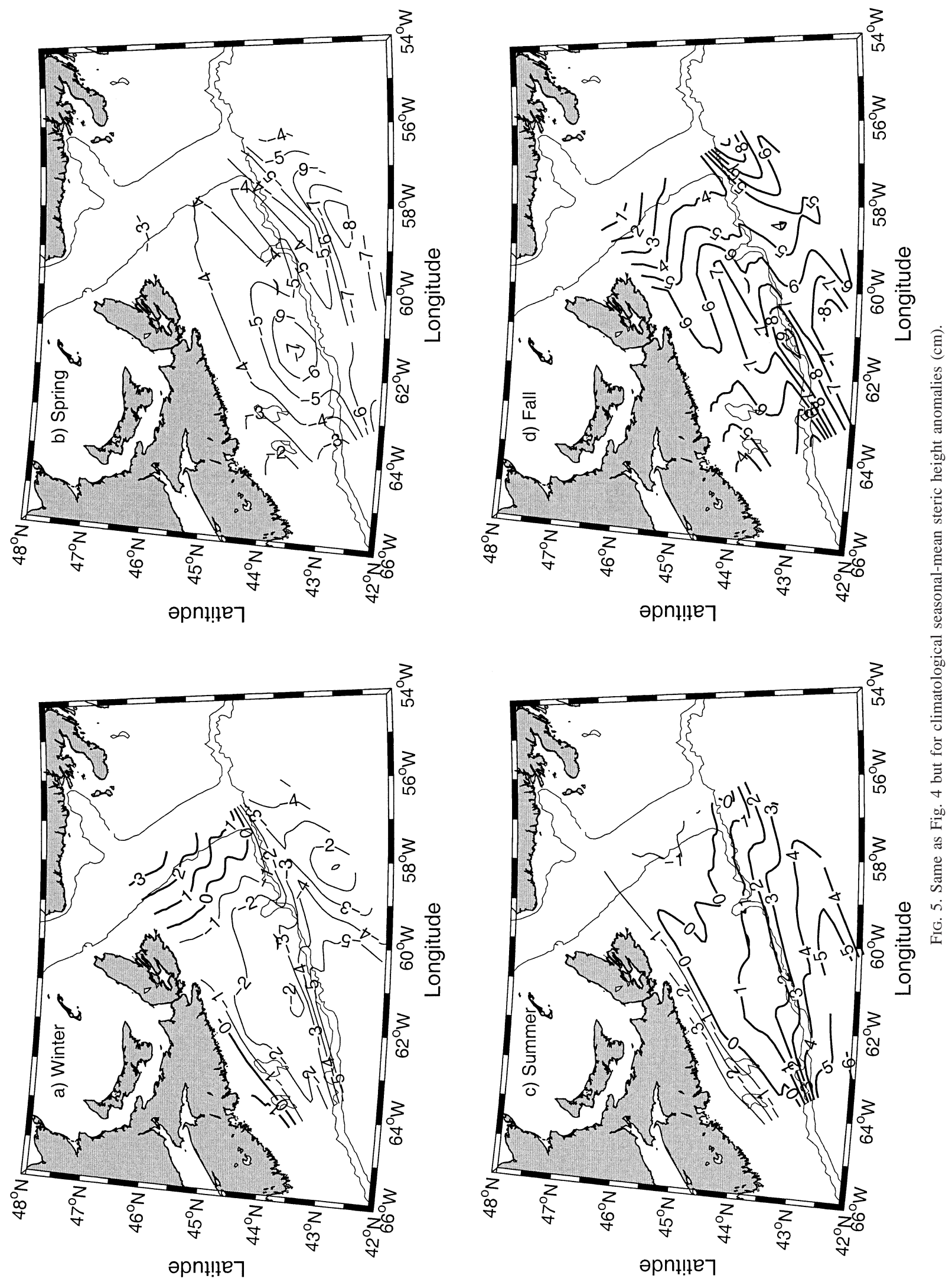

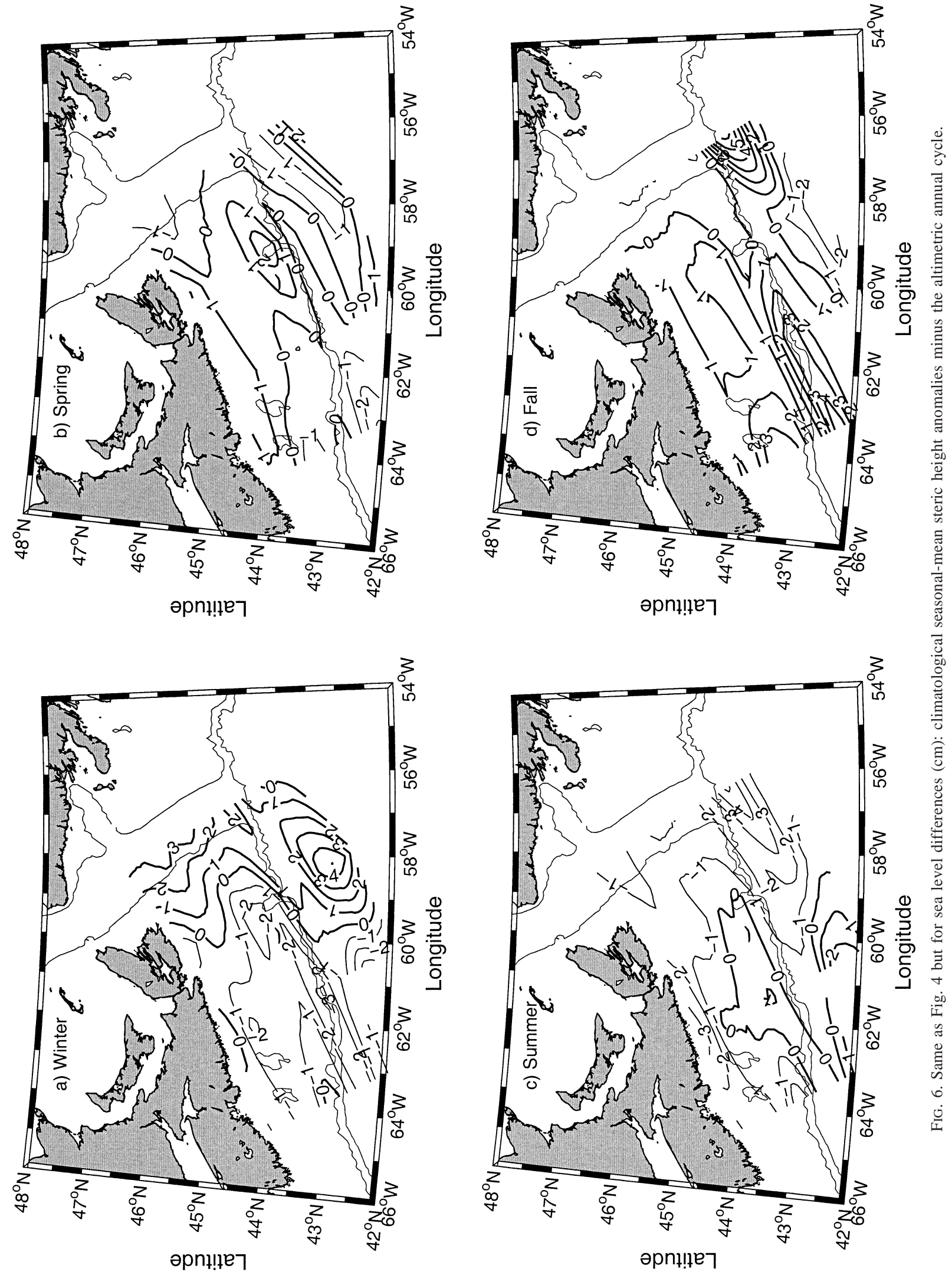
TABle 2. Amplitude (cm) and phase (the time of annual maximum sea level) of the annual sea level harmonic derived at St. John's, Newfoundland. TG: annual fit to monthly tide-gauge data for 1992-98 adjusted for the local inverse barometric effect. Steric height: annual fit to monthly steric height anomalies at Station 27 off St. John's, calculated by Petrie and Anderson (1983). Wind-driven: annual fit to monthly sea level anomalies in a linear barotropic model of Greatbatch and Goulding (1989).

\begin{tabular}{|c|c|c|c|c|c|}
\hline & $\mathrm{T} / \mathrm{P}$ & $\mathrm{TG}$ & Steric height & Wind-driven & $\begin{array}{l}\text { Steric height } \\
+ \text { wind-driven }\end{array}$ \\
\hline Amplitude & 6.5 & 7.3 & 4.9 & 3.1 & 5.7 \\
\hline Phase & Dec & Dec & Nov & Feb & Dec \\
\hline
\end{tabular}

\section{Annual variations of surface currents}

The geostrophic surface current anomaly normal to the satellite ground tracks is derived by computing the along-track gradient of the annual cycle of the sea surface height. Since the T/P data do not provide accurate information of the mean current because of the geoid error, we will use an independent mean surface current field from a diagnostic numerical model for the Scotian Shelf and southern Newfoundland Shelf.

The model consists of three-dimensional equations for continuity and momentum with the hydrostatic and Bousinesiq approximations. The equations are discretized and solved using the finite element approach (Naimie and Lynch 1993). The model domain (see Fig. 1) is discretized using a linear triangular mesh with variable grid size in the horizontal (Han and Loder, 2000 , unpublished manuscript) and constant $z / h$ ( $z$ vertical coordinate and $\mathrm{h}$ the local water depth) levels in the vertical. The model is driven with climatological seasonal density fields (same as those used to compute steric height fields) and sea surface slopes specified on model open boundaries. The specified surface slopes on the open boundaries are estimated from the seasonal density fields using geostrophic approximation and assuming no normal velocity at the sea bottom. See Han et al. (1999) and Han and Loder (2000, unpublished manuscript) for more detail. The model solutions provide detailed mean surface circulation patterns both on the shelf scale and on the topographic (bank) scale (Fig. 7a). On the shelf scale the mean surface current field from the numerical model shows dominant southwestward flows along the shelf edge $\left(\sim 30 \mathrm{~cm} \mathrm{~s}^{-1}\right)$, along the inner shelf $\left(\sim 15 \mathrm{~cm} \mathrm{~s}^{-1}\right)$ and a northeastward return current $\left(\sim 10 \mathrm{~cm} \mathrm{~s}^{-1}\right)$ over the Scotian Slope. Based on the model mean results, we have somewhat subjectively

TABLE 3. Amplitude (cm) and phase (the time of annual maximum sea level) of the annual sea level harmonic derived at Halifax, Nova Scotia. TG: annual fit to monthly tide-gauge data for 1992-98 adjusted for the local inverse barometric effect. Steric height: annual fit to monthly steric height anomalies at the nearest node to Halifax (Loder et al. 1997). Wind-driven: annual fit to monthly Sable Island wind stress anomalies for 1992-98 scaled by Smith and Schwing's (1991) gain (their Fig. 8).

\begin{tabular}{llccc}
\hline \hline & T/P & TG & Steric height & Wind-driven \\
\hline Amplitude & 4.5 & 2.5 & 4.8 & 0.2 \\
Phase & Nov & Dec & Dec & Apr \\
\hline
\end{tabular}

defined a cross-shelf window of the shelf-edge current (dashed lines in Fig. 7) for subsequent calculations of statistics of model-altimetry current differences. The coincidence of the mean slope current with the slope/shelf front is location dependent. The slope current magnitude of $\sim 10 \mathrm{~cm} \mathrm{~s}^{-1}$ is close to Pickart et al.'s estimate (1999). There is also evidence of multiple slope current branches, as found by Pickart et al. (1999). The nearshore current is mainly a baroclinic jet, resulting from the Gulf of St. Lawrence outflow (also see Figs. 8 and 9). The shelf edge current is the part of the northwest Atlantic's subpolar gyre, or the Labrador Current extension, with baroclinic and perhaps barotropic origin (Fig. 9).

The present altimetric surface current anomalies (Fig. 10) clearly show that the shelf-edge current off the Scotian Shelf, with a seasonal range of about $10-15 \mathrm{~cm}$ $\mathrm{s}^{-1}$, is stronger in winter and weaker in summer (Fig. 10). The winter-summer current variation amounts to $15-20 \mathrm{~cm} \mathrm{~s}^{-1}$ off the southwestern Newfoundland Shelf. The northeastward branch of the slope water gyre between the shelf-edge current and the shelf/slope front is stronger in fall and winter and weaker in the other seasons, with a seasonal range of $10 \mathrm{~cm} \mathrm{~s}^{-1}$. The accuracy of altimetric surface currents is estimated at 3 $\mathrm{cm} \mathrm{s}^{-1}$ based on the rms elevation error of $2 \mathrm{~cm}$ and a characteristic length scale of $75 \mathrm{~km}$. Therefore, the altimetric shelf-edge and slope water currents are statistically significant. In contrast, the current variability over the inner Scotian Shelf and the southern Grand Bank area is smaller and statistically insignificant; therefore we will not discuss it further.

The shelf-edge current variability derived from the $\mathrm{T} / \mathrm{P}$ altimetry is in good qualitative agreement with earlier studies using models, hydrography, and Geosat altimetry. These model results and observational studies have indicated dominant equatorward currents in this region. Csanady's (1979) steric setup model showed the onshore sea surface slope over the shelf break of the Scotian Shelf and southwest Grand Banks to be greater in spring than in summer. Han et al. (1993) reported their finding of the winter intensification of the shelfedge current from the Geosat altimeter data.

A detailed comparison of the altimetry-derived crosstrack current anomalies (Figs. 10a,c,d) with the linear diagnostic model solutions (Figs. 7b,c,d) also shows good qualitative and approximate quantitative agreement in the seasonality of the shelf-edge current. Both 

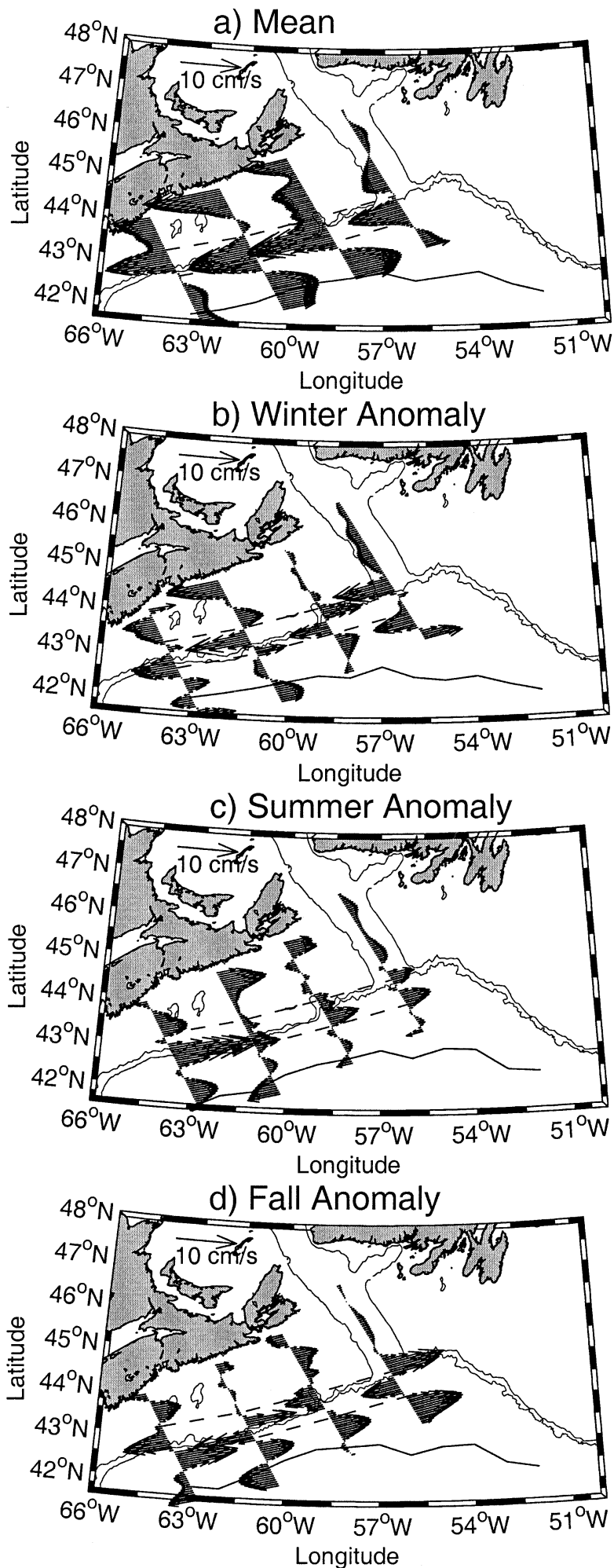

FIG. 7. Sea surface currents from the linear diagnostic model, interpolated onto the T/P ground tracks: (a) annual mean, (b) anomaly on 1 Feb, and (c) anomaly on 1 Aug. The dashed lines show the onshore window for the shelf-edge current, subjectively defined based on the model mean current profile. The solid lines are the shelf/slope front positions in corresponding seasons calculated using the shelf/slope front data (K. Drinkwater and R. Pettipas, 2000 personal communication) for the period from 1992 to 1998. altimetric and model results indicate a typical current anomaly of $\sim 5 \mathrm{~cm} \mathrm{~s}^{-1}$, southwestward in winter and northeastward in summer. The model - altimetry current differences (Fig. 11) show smaller-scale cross-shelf structure and are much less coherent alongshelf than either the model or altimetry current pattern, suggesting little systematic discrepancies. The mean difference between the altimetric and model shelf-edge currents, as defined by the cross-shelf window is $1.4 \mathrm{~cm} \mathrm{~s}^{-1}$ (Table 4), providing further quantitative evidence of consistency. Since the altimetry-derived current should include barotropic and baroclinic contributions, the implication of this first-order consistency is that the seasonal transport variability of the shelf-edge current is mainly baroclinic. Thus an additional barotropic transport may not be needed at the upstream open boundary in the numerical model, as has been suggested by recent moored measurements on the southwestern Newfoundland shelf edge (not shown). We note that the rms model - altimeter difference is significant compared to the rms altimetric current, but the rms difference appears to reflect differences in the cross-shelf location and extent of the altimetric and model current anomalies, and therefore is sensitive to the cross-shelf window chosen for the comparison. In fall when the shelf-edge current anomaly is less well defined, both the mean difference and the rms difference are much larger.

The altimetric results indicate that the slope water current anomaly has a broad cross-current and coherent along-current structure, with a typical mean anomaly of $4 \mathrm{~cm} \mathrm{~s}^{-1}$, southwestward in fall and northeastward in spring (Fig. 10). The intensified slope water current in fall is close to the shelf edge, consistent with the more northern position of slope/shelf front in this season. These physically plausible features together with the statistical significance of current magnitudes indicate the reliability of altimetric results. On the other hand, the model slope current anomaly shows smaller-scale cross-current and less coherent along-current distribution. The model - altimetry comparison also shows better agreement in fall [and spring (not shown)] when the slope current anomaly is larger (Table 4). But even in fall the rms difference is significantly larger than the rms altimetric current. The difference between the model and altimetric current anomalies (Table 4) suggests the model limitation in the diagnosis of the seasonal change of the slope water circulation. The model limitation is probably associated with the scarcity of hydrographic data in both space and time, and the use of zero bottom normal flow (an assumed reference level of no motion) on the model open boundary may also influence the results. The validity of using the assumption of no normal bottom current, that is, neglecting the contribution of additional barotropic currents through the boundary, may be evaluated in light of long-term and synoptic altimetric information for the study of the slope water circulation that is to date poorly understood. 


\section{CSW Section}
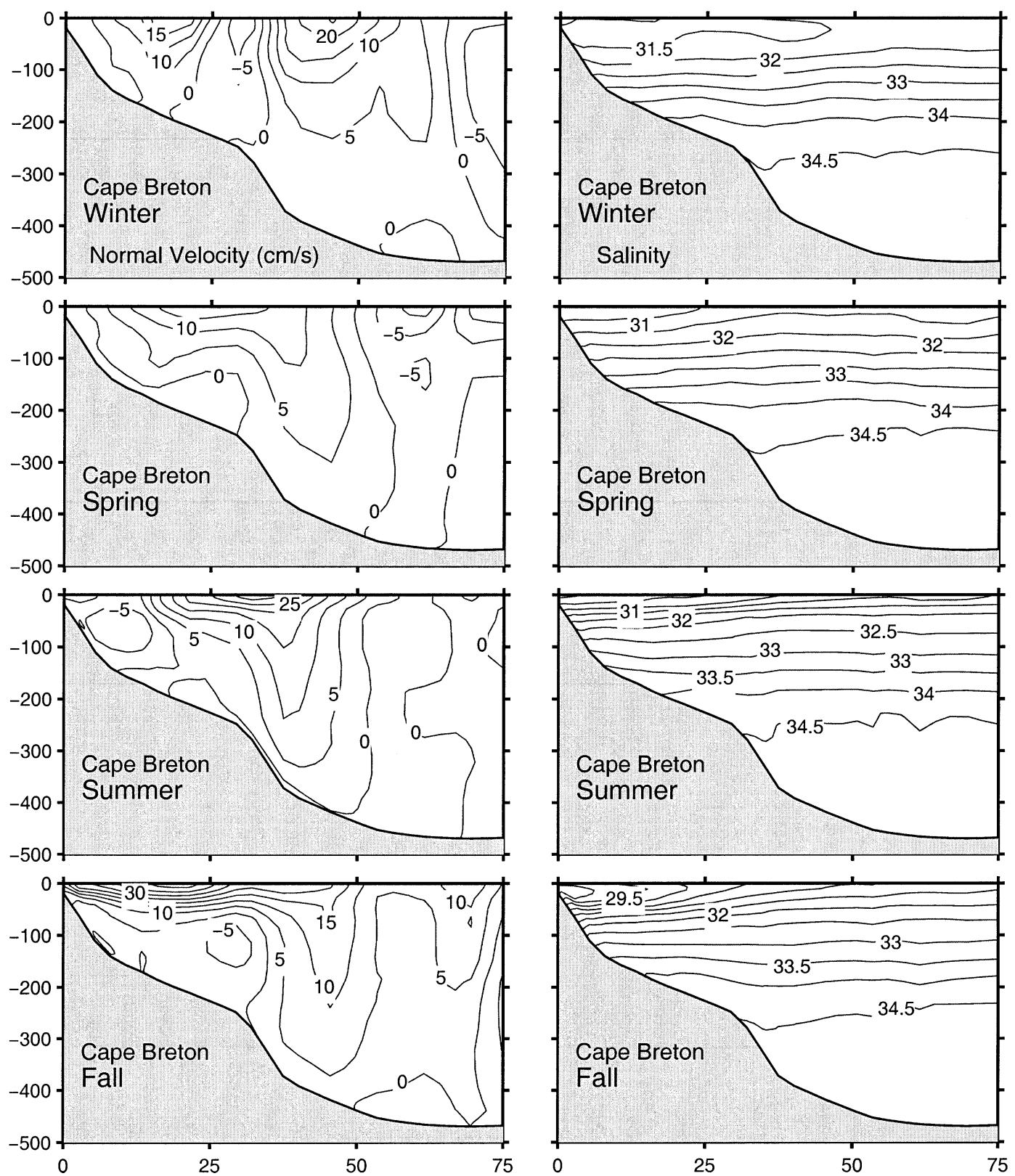

FIG. 8. Vertical distribution of the mean normal currents in winter, spring, summer, and fall from the linear diagnostic model on the Cabot Strait West section. Also shown are the model salinity values. The contour intervals are $5 \mathrm{~cm} \mathrm{~s}^{-1}$ for currents and 0.5 psu for salinity. Positive values indicate seaward currents. The horizontal and vertical axes are in kilometers and meters, respectively. See Fig. 1a for the section location.

Specifically, the altimetry-derived sea surface slope information could be used in a straightforward way to adjust barotropic current at the open boundary. The data scarcity problem in the slope water region will not be easily overcome. However, altimetric sea level variability is the surface manifestation of the integrated barotropic and baroclinic responses of ocean to all forcing factors. Therefore in a more sophisticated and challenging way, there is potential for recovering interior information by blending altimeter data into prognostic dynamic models. The models, initialized with hydrographic fields, serve as dynamic filters, interpolators, and predictors for achieving a statistical best fit among dynamics, altimetric data, and hydrographic data. Blending schemes in an assimilative ocean model, such as used by Ezer and Mellor (1997) for the Gulf Stream region, can be developed to infer the seasonal circulation and hydrographic variability over the Scotian Slope. 


\section{Halifax Section}
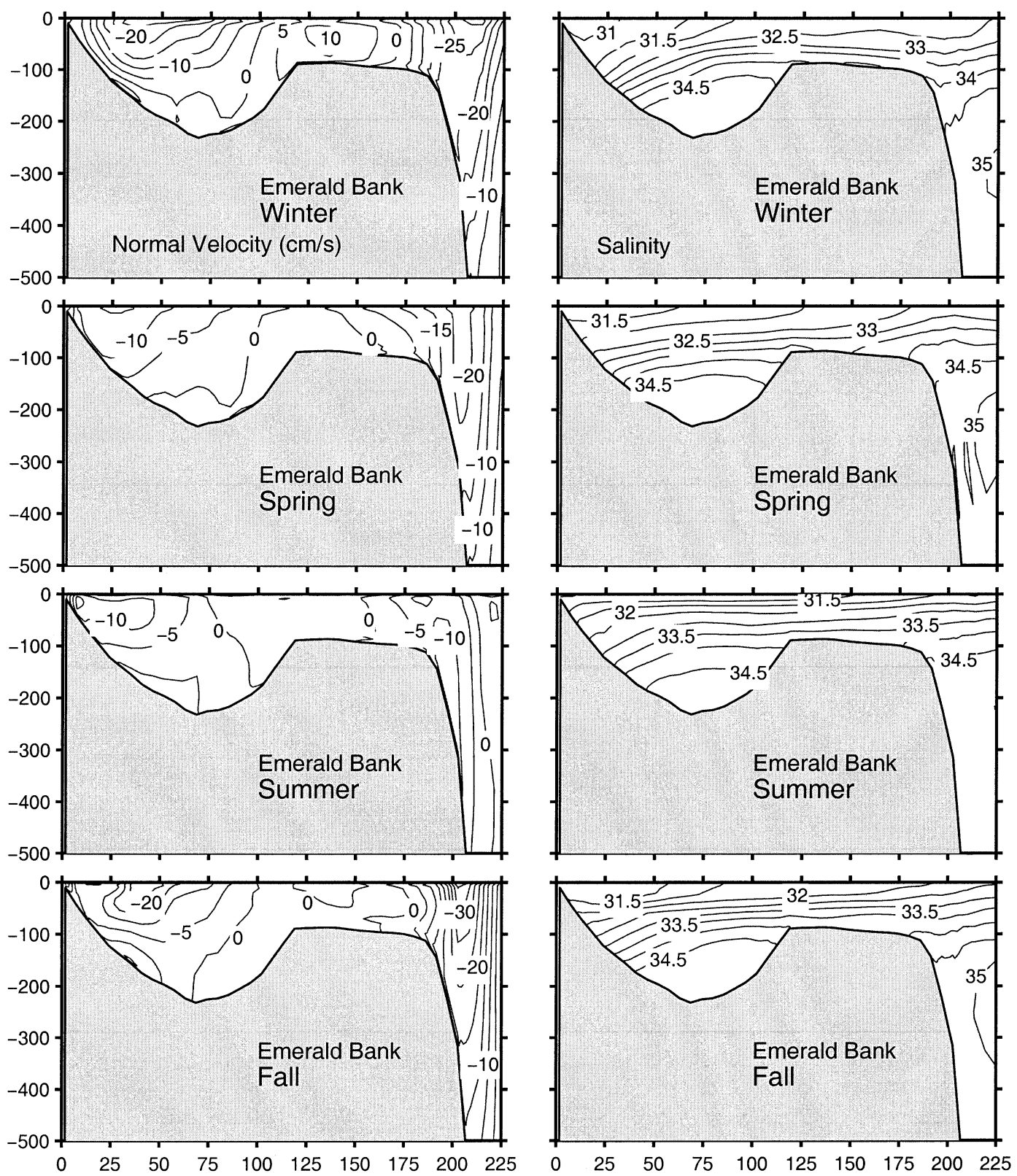

FIG. 9. Same as Fig. 8 but for the Halifax section with negative current values indicating southwestward flows. See Fig. 1a for the section location.

\section{Forcing mechanisms of coastal sea level changes}

Observational evidence (Trites and Banks 1958; Bumpus and Lauzier 1965) and numerical models (Han et al. 1999) have indicated that the outflow from Cabot Strait flows onto the Scotian Shelf in the upper water column. One of its major pathways is southwestward along the inner Scotian Shelf. The Cabot Strait outflow from the linear diagnostic model peaks in fall, as the salinity reaches a minimum in the surface layers (Fig.
8). During this season, the large upward slope of isohaline (and isopycnals) offshore compensates for a greater positive steric height slope toward the coast, in a dynamic balance with the stronger outflow. Indeed, the annual harmonic for the tide-gauge data at North Sydney (Table 1) shows that the sea level is highest in November, resulting in the largest positive slope onshore. At Halifax, the model solution indicates that the southwestward current over the inner shelf is intensified 

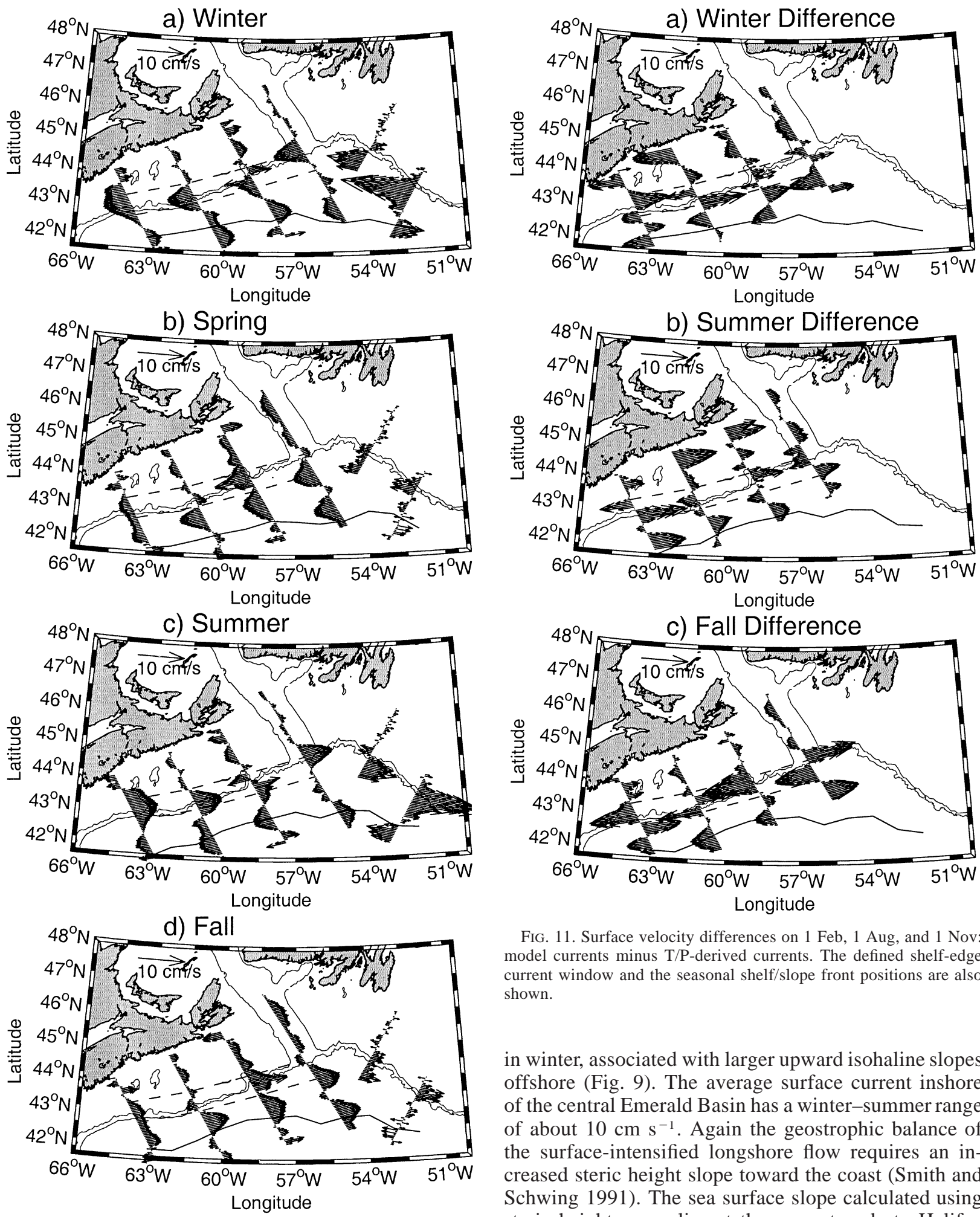

FIG. 11. Surface velocity differences on 1 Feb, 1 Aug, and 1 Nov: model currents minus T/P-derived currents. The defined shelf-edge current window and the seasonal shelf/slope front positions are also shown.

in winter, associated with larger upward isohaline slopes offshore (Fig. 9). The average surface current inshore of the central Emerald Basin has a winter-summer range of about $10 \mathrm{~cm} \mathrm{~s}^{-1}$. Again the geostrophic balance of the surface-intensified longshore flow requires an increased steric height slope toward the coast (Smith and Schwing 1991). The sea surface slope calculated using steric height anomalies at the nearest node to Halifax (Table 3) and in Emerald Basin (Figs. 5a and 5c) has a

FIG. 10. Cross-track sea surface current anomalies derived from the annual cycle of the altimetric sea level under geostrophy on (a) 1 Feb, (b) 1 May, (c) 1 Aug, and (d) 1 Nov. The defined shelf-edge current window and the seasonal shelf/slope front positions are also shown.

winter-summer range of $8 \mathrm{~cm}$ per $100 \mathrm{~km}$, confirming the approximate geostrophic balance. Therefore the sea level change along the Nova Scotia coast at the seasonal time scale is mainly associated with the fluctuation of 
TABLE 4. Statistics for altimetric shelf-edge and slope currents and for differences between numerical model and altimetric results. Negative values (in $\mathrm{cm} \mathrm{s}^{-1}$ ) indicate southwestward flow anomalies. AM: altimetric mean; MD: mean difference (model - altimeter); RMSA: altimetric rms; RMSD: rms difference. There are 56 and 60 data values used for shelf-edge and slope currents, respectively.

\begin{tabular}{|c|c|c|c|c|c|c|c|c|}
\hline & \multicolumn{4}{|c|}{ Winter } & \multicolumn{4}{|c|}{ Fall } \\
\hline & $\mathrm{AM}$ & $\mathrm{MD}$ & RMSA & RMSD & $\mathrm{AM}$ & MD & RMSA & RMSD \\
\hline Shelf-edge & -3.3 & -1.4 & 4.6 & 4.5 & 2.1 & -4.2 & 3.3 & 7.3 \\
\hline Slope & 2.0 & -1.3 & 2.5 & 4.1 & 2.2 & -0.5 & 3.1 & 4.5 \\
\hline
\end{tabular}

the Nova Scotian Current, driven by the low salinity outflow from the Gulf of St. Lawrence. The nonlocal boundary forced responses (e.g., freshwater inflow fluctuation) decrease along the Nova Scotia coast from the east to the west, while the coastal sea level response to the local alongshore wind stress increases to the west with nearly null setup at the eastern end of the shelf (Smith and Schwing 1991). Previous studies have shown that the coastal sea level setup in response to the local wind forcing is minor at the seasonal scale (e.g., Han et al. 1997), although it may become significant at the higher frequency (Thompson 1986). According to Smith and Schwing's (1991) results of applying coastaltrapped wave theory with nonlocal forcing to the Scotian Shelf, the annual sea level amplitude at Halifax and Yarmouth should be $60 \%$ and $40 \%$ of that at North Sydney, with a phase lag of 1.5 and 2 months, respectively. These theoretical predictions are generally consistent with the annual cycles derived from the tidegauge data: $4,2.4$, and $1.8 \mathrm{~cm}$ in amplitude and November, January, and February in phase at North Sydney, Halifax, and Yarmouth, respectively.

For the nearshore region along the southeastern and southern Newfoundland coast, the annual variation of the sea level seems to be associated with the inshore Labrador Current (change in steric height) and the winddriven setup due to wind forcing over the shelf and in the North Atlantic. The inshore Labrador Current is baroclinically driven and strongest in early fall (Petrie and Anderson 1983), while the wind-driven setup is essentially barotropic (Greatbatch and Goulding 1989) and reaches a maximum in the winter. The barotropic and baroclinic combination leads to the sea level maximum in late fall.

\section{Concluding remarks}

We have investigated the annual sea level variation over the Scotian Shelf and Slope and over the southern Newfoundland Shelf using the T/P altimeter data, tidegauge data, and hydrographic data. The cross-track geostrophic current anomaly is also calculated, and described together with the mean current from a diagnostic finite-element model over the outer Scotian Shelf and the Scotian Slope.

The analysis reveals a significant annual cycle of sea level over the Scotian Shelf and southern Newfoundland Shelf. The amplitude has a substantial spatial variation from nearly zero in the outer Laurentian Channel to about $7-10 \mathrm{~cm}$ near the shelf/slope front. The sea level change along the Nova Scotia coast is mainly attributed to the variation of the Nova Scotian Current forced by the low salinity outflow from the Gulf of St. Lawrence. The sea level peaks at North Sydney in early fall, at Halifax in late fall and at Yarmouth in winter, with generally decreasing magnitudes along the Nova Scotia coast. The sea level variability over the mid shelf is mainly associated with the steric height change high in fall and low in spring, which is a typical response of shelf water to the surface heating/cooling with a peculiar modification of seasonally variable fresher water passage. The coastal sea level off southeast Newfoundland has an annual cycle of up to $7 \mathrm{~cm}$, peaking in fall. The annual fluctuation is mainly associated with the combined effect of the steric height change and the barotropic ocean response to the wind forcing over the shelf and to a lesser extent in the North Atlantic.

The annual cycle of the cross-track geostrophic surface current is derived from the annual sea level change. The annual range is about $10 \mathrm{~cm} \mathrm{~s}^{-1}$ for the shelf edge current off the Scotian Shelf and southwest Newfoundland Shelf, largest in winter and weakest in summer. The altimetry-derived shelf edge current is consistent with diagnostic numerical model studies. Altimetric results also show a plausible seasonal cycle of the northeastward slope current of about $4 \mathrm{~cm} \mathrm{~s}^{-1}$ in amplitude strong in fall and winter and weak in spring and summer, which nevertheless is less well resolved in the diagnostic model solution. T/P altimetry's ability of providing robust information of slope current variability is particularly encouraging in consideration of our poor knowledge of slope water circulation.

TOPEX/Poseidon observations have a high alongtrack resolution, but a low cross-track resolution for the study of shelf processes. Within tens of kilometers from the coastline, little useful information can be obtained from the observations. The coastal tide-gauge measurements are expensive to maintain and sparsely and unevenly distributed, especially along the northern coast of Canada. Numerical hydrodynamic models may provide a detailed description of sea level variability, but with uncertainties in the open boundary conditions and parameterizations. A data assimilative model that blends the broadly distributed altimeter measurements with coastal tide-gauge data and other hydrographic observations and constrains the flow field and adjusts the 
hydrographic field by model dynamics is a promising tool for studying coastal sea level and circulation variability at various time and space scales. The general consistency among T/P satellite altimetry, tide-gauge data, and numerical hydrodynamic models over the Scotian Shelf and Slope warrants using this region as a test bed for such dynamically consistent data blending.

The present analysis of T/P altimetry data demonstrates the capability of the global tide model in detiding satellite altimetry data over most of the continental shelf areas, but clearly indicates the weakness in some nearshore regions especially off Cape Cod and over Georges Bank. Although this weakness seems not critical to the study of the annual cycle in the present paper and longerterm variability as a result of the distinct alias patterns of the major tidal constituents, it is a problem for the study of natural semiannual and shorter-period changes. Therefore, the present study reveals a demand for higher-accuracy coastal and shelf tidal models that are compatible with global models for detiding satellite altimetry.

Acknowledgments. We would like to thank Roger Pettipas for processing the tide-gauge data and slope/shelf front data, Shawn Oakey for making the sectional plots of the numerical model results, Brian Petrie for providing useful comments, and John Loder and Gary Budgen for helpful internal reviews. Helpful suggestions were received from two anonymous reviewers. This study was funded under the (Canadian) Federal Panel on Energy Research and Development. The T/P data were obtained from NASA Jet Propulsion Lab and Pathfinder Project.

\section{REFERENCES}

Benada, R., 1997: Merged GDR (TOPEX/Poseidon) Users Handbook. Jet Propulsion Laboratory Rep. JPL D-11007, Pasadena, CA, $124 \mathrm{pp}$.

Brown, W. S., 1998: Wind-forced pressure response of the Gulf of Maine. J. Geophys. Res., 103 (C13), 30 661-30 678.

Bumpus, D. E., and L. M. Lauzier, 1965: Surface circulation on the continental shelf off eastern North America between Newfoundland and Florida. Serial Atlas of the Marine Environment, Amer. Geogr. Soc., Folio 7, Plate 8, 4 pp.

Cartwright, D. E., and R. D. Ray, 1990: Oceanic tides from Geosat altimetry. J. Geophys. Res., 95, 3069-3090.

Csanady, G. T., 1979: The pressure field along the western margin of the North Atlantic. J. Geophys. Res., 84 (C8), 4905-4915.

de Margerie, S., and K. D. Lank, 1986: Tidal circulation of the Scotian Shelf and Grand Bank. Contract Report to the Department of Fisheries and Oceans of Canada, Contract 08SC, FD901-5-X515, $\mathrm{v}+44 \mathrm{pp}$.
Drinkwater, K., B. Petrie, and W. H. Sutcliffe Jr., 1979: Seasonal geostrophic volume transport along the Scotian Shelf. Estuar. Coastal Mar. Sci., 9, 17-27.

Ezer, T., and G. Mellor, 1997: Data assimilation experiments in the Gulf Stream region: How useful are satellite-derived surface data for nowcasting the subsurface fields? J. Atmos. Oceanic Technol., 14, 1379-1391.

Greatbatch, R. J., and A. Goulding, 1989: Seasonal variations in a linear barotropic model of the North Atlantic driven by the Hellerman and Rosenstein wind stress field. J. Phys. Oceanogr., 19, $572-595$.

Han, G., and C. L. Tang, 1999: Velocity and transport variability of the Labrador Current determined from altimetric, hydrographic, and wind data. J. Geophys. Res., 104 (C8), 18 047-18 057.

_, M. Ikeda, and P. C. Smith, 1993: Annual variation of sea-surface slopes over the Scotian Shelf and Grand Banks from Geosat altimetry. Atmos.-Ocean, 31, 591-615.

,$- \cdots$, and -1996 : Oceanic tides from TOPEX/POSEIDON altimetry over the Scotian Shelf and Grand Banks. Atmos.Ocean, 34, 589-604.

, C. G. Hannah, J. W. Loder, and P. C. Smith, 1997: Seasonal variation of the three-dimensional mean circulation over the Scotian Shelf. J. Geophys. Res., 102 (C1), 1011-1025.

_ J. W. Woder, and P. C. Smith, 1999: Seasonal-mean hydrography and circulation in the Gulf of St. Lawrence and eastern Scotian and southern Newfoundland Shelves. J. Phys. Oceanogr., 29, 1279-1301.

_, R. Hendry, and M. Ikeda, 2000: Assimilating TOPEX/POSEIDON derived tides in a primitive equation model over the Newfoundland Shelf. Cont. Shelf Res., 20, 84-108.

Loder, J. W., G. Han, C. G. Hannah, D. A. Greenberg, and P. C. Smith, 1997: Hydrography and baroclinic circulation in the Scotian Shelf region: Winter vs summer. Can. J. Fish. Aquat. Sci., 54 (Suppl. 1), 40-56.

— B. D. Petrie, and G. Gawarkiewicz, 1998: The coastal ocean off northeastern North America: A large-scale view. The Sea, K. H. Brink and A. R. Robinson, Eds., Regional Studies and Syntheses, Vol. 11, John Wiley and Sons, 105-133.

Naimie, C. E., and D. R. Lynch, 1993: FUNDY5 users' manual. Numerical Methods Laboratory, Dartmouth College, 40 pp.

Petrie, B., and C. Anderson, 1983: Circulation on the Newfoundland Continental Shelf. Atmos.-Ocean, 21, 207-226.

Pickart, R. S., T. K. McKee, D. J. Torres, and S. A. Harrington, 1999: Mean structure and interannual variability of the slopewater system south of Newfoundland. J. Phys. Oceanogr., 29, 2541-2558.

Schrama, E. J. O., and R. D. Ray, 1994: A preliminary tidal analysis of TOPEX/POSEIDON altimetry. J. Geophys. Res., 99 (C12), 24 799-24 808.

Schwiderski, E. W., 1980: On charting global ocean tides. Rev. Geophys. Space Phys., 18, 243-268.

Smith, P. C., and F. B. Schwing, 1991: Mean circulation and variability on the eastern Canadian continental shelf. Cont. Shelf Res., 11, 977-1012.

Sutcliffe, W. H., Jr., R. H. Loucks, and K. F. Drinkwater, 1976: Coastal circulation and physical oceanography of the Scotian Shelf and Gulf of Maine. J. Fish. Res. Board Can., 33, 98-115.

Thompson, K. R., 1986: North Atlantic sea-level and circulation. Geophys. J. Roy. Astron. Soc., 87, 15-32.

Trites, R. W., and R. E. Banks, 1958: Circulation on the Scotian Shelf as indicated by drift bottles. J. Fish. Res. Board Can., 15, 7989. 